\title{
In vitro prediction of drug-induced cholestatic liver injury: a challenge for the toxicologist
}

\author{
Mathieu Vinken ${ }^{1}$
}

Received: 20 March 2018 / Accepted: 22 March 2018 / Published online: 24 March 2018

c) Springer-Verlag GmbH Germany, part of Springer Nature 2018

Keywords Cholestasis · Adverse outcome pathway · In vitro toxicology

\author{
Abbreviations \\ AOP(s) Adverse outcome pathway(s) \\ DILI Drug-induced liver injury \\ KE(s) Key event(s) \\ KER(s) Key event relationship(s) \\ MIE(s) Molecular initiating event(s)
}

Cholestasis is derived from the Greek words chole meaning bile and stasis indicating halting (Noor 2015), and denotes any situation of impaired bile secretion with concomitant accumulation of bile acids in the liver or in the systemic circulation. A variety of factors may evoke cholestasis, including genetic disorders, metabolic pathologies, infectious diseases, immunogenic stimuli and drugs (Anthérieu et al. 2013; Gossard and Talwalkar 2014; Nguyen et al. 2014; Noor 2015). Drugs can induce either acute or chronic cholestasis, whereby symptoms resolve upon drug withdrawal or persist for periods over 6 months despite drug retraction, respectively. Acute drug-induced cholestasis occurs most frequently and manifests with or without hepatocellular and inflammatory injury, and is associated with vague symptoms, including nausea, malaise, anorexia and fatigue. Chronic drug-induced cholestasis occurs as a result of injury to bile ducts or ductules with clinical features such as pruritus, jaundice, melanoderma and xanthoma formation (Bhamidimarri and Schiff 2013; Gossard and Talwalkar 2014; Yang et al. 2013).

Drug-induced cholestasis constitutes a subgroup of druginduced liver injury (DILI). DILI is a major reason of drug failure during premarketing and postmarketing phases,

Mathieu Vinken

mvinken@vub.ac.be

1 Department of In Vitro Toxicology

and Dermato-Cosmetology, Vrije Universiteit Brussel,

Laarbeeklaan 103, 1090 Brussels, Belgium accounting for up to $29 \%$ of all drug withdrawals (Lee 2013; Van den Hof et al. 2015). In addition to its pharmaceutical relevance, DILI is also of high clinical concern. Indeed, DILI is frequently misdiagnosed, yet it has been estimated to develop in 1 in 100 patients during hospitalization (Meier et al. 2005). Furthermore, DILI is responsible for more than $50 \%$ of all cases of acute liver failure (Goldberg et al. 2015). As such, 20-40\% and 12-20\% of DILI patients presents a cholestatic and mixed hepatocellular/cholestatic injury pattern, respectively (Bhamidimarri and Schiff 2013; Sharanek et al. 2016). Cholestatic DILI is seen most frequently among men over 60 years old (Meier et al. 2005). The overall mortality rate of DILI attributed to cholestasis is $2.5-7.8 \%$ (Bhamidimarri and Schiff 2013; Björnsson and Olsson 2005; Noor 2015; Sharanek et al. 2016; Wolters et al. 2016). Although more than 1 drug can be involved in DILI, single prescription medication underlies $73 \%$ of all drug-induced cholestasis cases. More than 1000 drugs have been associated with cholestatic liver injury, including anti-infectious drugs, anti-diabetics, anti-inflammatory drugs, psychotropic drugs, cardiovascular drugs and steroids (Bhamidimarri and Schiff 2013; Parmentier et al. 2017).

Preclinical animal models only allow to predict 50-60\% of human DILI cases because of interspecies differences. Likewise, current human-based hepatic in vitro models merely pick up half of clinical DILI events (Laverty et al. 2010; Xu et al. 2004). The latter obviously can be attributed to overall in vitro-in vivo differences, but may also be due to gaps in the mechanistic understanding of DILI, in casu cholestasis. A pragmatic tool to rationally and visually capture existing knowledge regarding the mechanistic basis of toxicity includes the so-called adverse outcome pathway (AOP), which starts from a molecular initiating event (MIE) (i.e. a trigger of toxicity) and that relies on a series of key events (KEs), linked by key event relationships (KERs), ultimately resulting in a specific toxicological effect (Ankley et al. 2010; Gijbels and Vinken 2017; Leist et al. 2017; 
Vinken et al. 2017; Vinken 2013, 2015, 2016). A number of AOPs related to hepatotoxicity, including liver steatosis, liver fibrosis and cholestasis, have been proposed (Gijbels and Vinken 2017). Most currently available AOPs consider only 1 MIE. Clearly, this is not a full reflection of the actual in vivo situation, as toxicological effects are not as straightforward as depicted in AOPs. An improvement came with the introduction of AOP networks, which combine different AOPs that share at least $1 \mathrm{KE}$ (Villeneuve et al. 2014). Such AOP networks have been described for liver steatosis and seem to provide an in vivo-complying mechanistic scenario (Mellor et al. 2016). Other types of hepatotoxicity, however, in particular cholestasis, are more complex. Indeed, bile accumulation triggers 2 types of cellular responses, namely an adverse response and an adaptive response, which occur in parallel and that each are typified by a number of KEs (Vinken et al. 2013). Thus, the adverse response is accompanied by the onset of processes such as oxidative stress (Allen et al. 2010; Cai et al. 2017; Kim et al. 2006; Tan et al. 2010; Woolbright and Jaeschke 2012), inflammation (Gong et al. 2016; Li et al. 2017) and different cell death modes (Gujral et al. 2004; Mitchell et al. 2011; Woolbright et al. 2013, 2015). On the other hand, the adaptive response, aimed at decreasing the uptake and increasing the export of bile acids into and from hepatocytes, respectively, depends on the activation of several nuclear receptors, including the farnesoid $\mathrm{X}$ receptor, the pregnane $\mathrm{X}$ receptor and the constitutive androstane receptor (Boyer 2009; Cuperus et al. 2014; Wagner et al. 2009; Zollner and Trauner 2006, 2008). As a result, mechanistic modelling of cholestasis in AOP networks is challenging, as this should take into account the entangled pathways that drive these cellular responses as taking place in vivo. Furthermore, a number of potentially new cholestatic MIEs, like altered bile canaliculi dynamics (Burban et al. 2017; Burbank et al. 2016; Sharanek et al. 2016), as well as KEs, such as necroptosis and autophagy (Afonso et al. 2016; Gao et al. 2014; Lin et al. 2012; Manley et al. 2014; Sasaki et al. 2015), have been identified in the last few years. This adds to the mechanistic complexity of cholestasis and more mechanisms may emerge in the upcoming years given the worldwide increasing research efforts in this area.

AOPs and their networks can serve as the basis for setting up batteries of in vitro tests, each that detects 1 or more KEs, and which collectively may enable accurate prediction of toxicity inflicted by chemicals. A prerequisite in this respect is the use of in vitro models that appropriate reproduce in vivo cholestatic liver injury. A number of state-of-the-art in vitro models to study hepatotoxicity induced by chemicals belonging to 2 classes are presently available, namely liver-derived in vitro models and stem cell-derived in vitro models. Stem cell-derived in vitro models have shown their value for studying different types of liver toxicity, including liver steatosis (Pradip et al. 2015; Rodrigues et al. 2014). However, although some studies demonstrated their promise (Ghodsizadeh et al. 2010; Imagawa et al. 2017), hepatocyte-like cells derived from induced pluripotent stem cells have been reported not to be the most appropriate in vitro systems for the detection of cholestatic chemicals (Bell et al. 2017), which is due in part to their inability to properly trigger the adaptive response, being critical for the actual manifestation of cholestatic liver toxicity. This is unlike most liver-derived in vitro models (Godoy et al. 2013), which are more suitable tools for the screening of cholestatic compounds. These liver-derived in vitro models include cultures of human hepatoma HepaRG cells (Woolbright et al. 2016), freshly isolated human liver slices (Vatakuti et al. 2017), primary human hepatocytes "sandwiched" (i.e. cultured) between 2 layers of extracellular matrix components (Chatterjee et al. 2014; Oorts et al. 2016) and spheroid cultures of primary human hepatocytes (Bell et al. 2016; Hendriks et al. 2016). Because of their longevity, the presence of an in vivo-like tridimensional cellular configuration and cellular interactions as well as of bile ductules (Fraczek et al. 2013), sandwich and spheroid cultures of primary human hepatocytes are currently considered as the best performing in vitro systems to detect cholestatic compounds. In fact, it has been shown that the sensitivity for cholestatic effects in spheroid cultures of primary human hepatocytes increases with exposure time (Hendriks et al. 2016), which may be associated with the occurrence of the adaptive response.

Future strategies to improve in vitro predictivity of in vivo drug-induced cholestatic liver injury should in first instance focus on the full elucidation of the underlying mechanisms of cholestasis in an AOP network framework. This will yield series of KE-specific biomarkers, which can be picked up by "omics" technologies and that altogether can form a mechanistic signature of drug-induced cholestatic liver injury. The resulting AOP network on cholestasis should be ideally embedded in structures that also consider other aspects of toxicity, in particular kinetics and exposure parameters. Simultaneously, current in vitro models must be further improved for application in the detection of cholestatic potential of chemicals. This particularly holds for stem cell-derived in vitro models. Furthermore, in vitro testing approaches should be complemented with emerging in silico methods that computationally predict cholestatic potential based on chemical structures and/or physico-chemical profiles. It can be anticipated that full integration of new knowledge and methodologies in the upcoming years will enable early and accurate detection of the cholestatic potential of drugs and chemicals in general. This will not only increase human chemical safety as such, but will equally reduce and even fully replace the use of animals for toxicity testing. 


\section{References}

Afonso MB, Rodrigues PM, Simão AL, Ofengeim D, Carvalho T, Amaral JD, Gaspar MM, Cortez-Pinto H, Castro RE, Yuan J, Rodrigues CM (2016) Activation of necroptosis in human and experimental cholestasis. Cell Death Dis 7:e2390

Allen K, Kim ND, Moon JO, Copple BL (2010) Upregulation of early growth response factor- 1 by bile acids requires mitogen-activated protein kinase signaling. Toxicol Appl Pharmacol 243:63-67

Ankley GT, Bennett RS, Erickson RJ, Hoff DJ, Hornung MW, Johnson RD, Mount DR, Nichols JW, Russom CL, Schmieder PK, Serrrano JA, Tietge JE, Villeneuve DL (2010) Adverse outcome pathways: a conceptual framework to support ecotoxicology research and risk assessment. Environ Toxicol Chem 29:730-741

Anthérieu S, Bachour-El Azzi P, Dumont J, Abdel-Razzak Z, GuguenGuillouzo C, Fromenty B, Robin MA, Guillouzo A (2013) Oxidative stress plays a major role in chlorpromazine-induced cholestasis in human HepaRG cells. Hepatology 57:1518-1529

Bell CC, Hendriks DF, Moro SM, Ellis E, Walsh J, Renblom A, Fredriksson Puigvert L, Dankers AC, Jacobs F, Snoeys J, SisonYoung RL, Jenkins RE, Nordling A, Mkrtchian S, Park BK, Kitteringham NR, Goldring CE, Lauschke VM, Ingelman-Sundberg M (2016) Characterization of primary human hepatocyte spheroids as a model system for drug-induced liver injury, liver function and disease. Sci Rep 6:25187

Bell CC, Lauschke VM, Vorrink SU, Palmgren H, Duffin R, Andersson TB, Ingelman-Sundberg M (2017) Transcriptional, functional, and mechanistic comparisons of stem cell-derived hepatocytes, HepaRG Cells, and three-dimensional human hepatocyte spheroids as predictive in vitro systems for drug-induced liver injury. Drug Metab Dispos 45:419-429

Bhamidimarri KR, Schiff E (2013) Drug-induced cholestasis. Clin Liver Dis 17:519-531

Björnsson E, Olsson R (2005) Outcome and prognostic markers in severe drug-induced liver disease. Hepatology 42:481-489

Boyer IL (2009) It's all about bile. Hepatology 49:711-723

Burban A, Sharanek A, Hüe R, Gay M, Routier S, Guillouzo A, Guguen-Guillouzo C (2017) Penicillinase-resistant antibiotics induce non-immune-mediated cholestasis through HSP27 activation associated with PKC/P38 and PI3K/AKT signaling pathways. Sci Rep 7:1815

Burbank MG, Burban A, Sharanek A, Weaver RJ, Guguen-Guillouzo C, Guillouzo A (2016) Early alterations of bile canaliculi dynamics and the rho kinase/myosin light chain kinase pathway are characteristics of drug-induced intrahepatic cholestasis. Drug Metab Dispos 44:1780-1793

Cai SY, Ouyang X, Chen Y, Soroka CJ, Wang J, Mennone A, Wang Y, Mehal WZ, Jain D, Boyer JL (2017) Bile acids initiate cholestatic liver injury by triggering a hepatocyte-specific inflammatory response. JCI Insight 2:e90780

Chatterjee S, Richert L, Augustijns P, Annaert P (2014) Hepatocytebased in vitro model for assessment of drug-induced cholestasis. Toxicol Appl Pharmacol 274:124-136

Cuperus FJ, Claudel T, Gautherot J, Halilbasic E, Trauner M (2014) The role of canalicular ABC transporters in cholestasis. Drug Metab Dispos 42:546-560

Fraczek J, Bolleyn J, Vanhaecke T, Rogiers V, Vinken M (2013) Primary hepatocyte cultures for pharmaco-toxicological studies: at the busy crossroad of various anti-dedifferentiation strategies. Arch Toxicol 87:577-610

Gao L, Lv G, Guo X, Jing Y, Han Z, Zhang S, Sun K, Li R, Yang Y, Wei L (2014) Activation of autophagy protects against cholestasis-induced hepatic injury. Cell Biosci 4:47

Ghodsizadeh A, Taei A, Totonchi M, Seifinejad A, Gourabi H, Pournasr B, Aghdami N, Malekzadeh R, Almadani N, Salekdeh GH,
Baharvand H (2010) Generation of liver disease-specific induced pluripotent stem cells along with efficient differentiation to functional hepatocyte-like cells. Stem Cell Rev 6:622-632

Gijbels E, Vinken M (2017) An update on adverse outcome pathways leading to liver injury. Appl In Vitro Toxicol 3:283-285

Godoy P, Hewitt NJ, Albrecht U, Andersen ME, Ansari N, Bhattacharya S, Bode JG, Bolleyn J, Borner C, Böttger J, Braeuning A, Budinsky RA, Burkhardt B, Cameron NR, Camussi G, Cho CS, Choi YJ, Craig Rowlands J, Dahmen U, Damm G, Dirsch O, Donato MT, Dong J, Dooley S, Drasdo D, Eakins R, Ferreira KS, Fonsato V, Fraczek J, Gebhardt R, Gibson A, Glanemann M, Goldring CE, Gómez-Lechón MJ, Groothuis GM, Gustavsson L, Guyot C, Hallifax D, Hammad S, Hayward A, Häussinger D, Hellerbrand C, Hewitt P, Hoehme S, Holzhütter HG, Houston JB, Hrach J, Ito K, Jaeschke H, Keitel V, Kelm JM, Kevin Park B, Kordes C, Kullak-Ublick GA, LeCluyse EL, Lu P, LuebkeWheeler J, Lutz A, Maltman DJ, Matz-Soja M, McMullen P, Merfort I, Messner S, Meyer C, Mwinyi J, Naisbitt DJ, Nussler AK, Olinga P, Pampaloni F, Pi J, Pluta L, Przyborski SA, Ramachandran A, Rogiers V, Rowe C, Schelcher C, Schmich K, Schwarz M, Singh B, Stelzer EH, Stieger B, Stöber R, Sugiyama Y, Tetta C, Thasler WE, Vanhaecke T, Vinken M, Weiss TS, Widera A, Woods CG, Xu JJ, Yarborough KM, Hengstler JG (2013) Recent advances in $2 \mathrm{D}$ and $3 \mathrm{D}$ in vitro systems using primary hepatocytes, alternative hepatocyte sources and non-parenchymal liver cells and their use in investigating mechanisms of hepatotoxicity, cell signaling and ADME. Arch Toxicol 87:1315-1530

Goldberg DS, Forde KA, Carbonari DM, Lewis JD, Leidl KB, Reddy KR, Haynes K, Roy J, Sha D, Marks AR, Schneider JL, Strom BL, Corley DA, Lo Re V 3rd (2015) Population-representative incidence of drug-induced acute liver failure based on an analysis of an integrated health care system. Gastroenterology 148:1353-1361

Gong Z, Zhou J, Zhao S, Tian C, Wang P, Xu C, Chen Y, Cai W, Wu J (2016) Chenodeoxycholic acid activates NLRP3 inflammasome and contributes to cholestatic liver fibrosis. Oncotarget 7:83951-83963

Gossard AA, Talwalkar JA (2014) Cholestatic liver disease. Med Clin North Am 98:73-85

Gujral JS, Liu J, Farhood A, Jaeschke H (2004) Reduced oncotic necrosis in Fas receptor-deficient C57BL/6J-lpr mice after bile duct ligation. Hepatology 40:998-1007

Hendriks DF, Fredriksson Puigvert L, Messner S, Mortiz W, IngelmanSundberg M (2016) Hepatic 3D spheroid models for the detection and study of compounds with cholestatic liability. Sci Rep 6:35434

Imagawa K, Takayama K, Isoyama S, Tanikawa K, Shinkai M, Harada K, Tachibana M, Sakurai F, Noguchi E, Hirata K, Kage M, Kawabata K, Sumazaki R, Mizuguchi H (2017) Generation of a bile salt export pump deficiency model using patient-specific induced pluripotent stem cell-derived hepatocyte-like cells. Sci Rep 7:41806

Kim ND, Moon JO, Slitt AL, Copple BL (2006) Early growth response factor- 1 is critical for cholestatic liver injury. Toxicol Sci 90:586-595

Laverty HG, Antoine DJ, Benson C, Chaponda M, Williams D, Kevin Park B (2010) The potential of cytokines as safety biomarkers for drug-induced liver injury. Eur J Clin Pharmacol 66:961-976

Lee WM (2013) Drug-induced acute liver failure. Clin Liver Dis 17:575-586

Leist M, Ghallab A, Graepel R, Marchan R, Hassan R, Bennekou SH, Limonciel A, Vinken M, Schildknecht S, Waldmann T, Danen E, van Ravenzwaay B, Kamp H, Gardner I, Godoy P, Bois FY, Braeuning A, Reif R, Oesch F, Drasdo D, Höhme S, Schwarz M, Hartung T, Braunbeck T, Beltman J, Vrieling H, Sanz F, Forsby A, Gadaleta D, Fisher C, Kelm J, Fluri D, Ecker G, Zdrazil B, 
Terron A, Jennings P, van der Burg B, Dooley S, Meijer AH, Willighagen E, Martens M, Evelo C, Mombelli E, Taboureau O, Mantovani A, Hardy B, Koch B, Escher S, van Thriel C, Cadenas C, Kroese D, van de Water B, Hengstler JG (2017) Adverse outcome pathways: opportunities, limitations and open questions. Arch Toxicol 91:3477-3505

Li P, He K, Li J, Liu Z, Gong J (2017) The role of Kupffer cells in hepatic diseases. Mol Immunol 85:222-229

Lin TK, Huang LT, Huang YH, Tiao MM, Tang KS, Liou CW (2012) The effect of the red wine polyphenol resveratrol on a rat model of biliary obstructed cholestasis: involvement of anti-apoptotic signalling, mitochondrial biogenesis and the induction of autophagy. Apoptosis 17:871-879

Manley S, Ni HM, Kong B, Apte U, Guo G, Ding WX (2014) Suppression of autophagic flux by bile acids in hepatocytes. Toxicol Sci 137:478-490

Meier Y, Cavallaro M, Roos M, Pauli-Magnus C, Folkers G, Meier PJ, Fattinger K (2005) Incidence of drug-induced liver injury in medical inpatients. Eur J Clin Pharmacol 61:135-143

Mellor CL, Steinmetz FP, Cronin MT (2016) The identification of nuclear receptors associated with hepatic steatosis to develop and extend adverse outcome pathways. Crit Rev Toxicol 46:138-152

Mitchell C, Mahrouf-Yorgov M, Mayeuf A, Robin MA, Mansouri A, Fromenty B, Gilgenkrantz H (2011) Overexpression of Bcl-2 in hepatocytes protects against injury, but does not attenuate fibrosis in a mouse model of chronic cholestatic liver disease. Lab Invest 91:273-282

Nguyen KD, Sundaram V, Ayoub WS (2014) Atypical causes of cholestasis. World J Gastroenterol 20:9418-9426

Noor F (2015) A shift in paradigm towards human biology-based systems for cholestatic liver diseases. J Physiol 593:5043-5055

Oorts M, Baze A, Bachellier P, Heyd B, Zacharias T, Annaert P, Richert L (2016) Drug-induced cholestasis risk assessment in sandwich-cultured human hepatocytes. Toxicol In Vitro 34:179-186

Parmentier C, Couttet P, Wolf A, Zaccharias T, Heyd B, Bachellier P, Uteng M, Richert L (2017) Evaluation of transcriptomic signature as a valuable tool to study drug-induced cholestasis in primary human hepatocytes. Arch Toxicol 91:2879-2893

Pradip A, Steel D, Jacobsson S, Holmgren G, Ingelman-Sundberg M, Sartipy P, Björquist P, Johansson I, Edsbagge J (2016) High-content analysis of human pluripotent stem cell-derived hepatocytes reveals drug-induced steatosis and phospholipidosis. Stem Cells Int 2475631

Rodrigues RM, De Kock J, Branson S, Vinken M, Meganathan K, Chaudhari U, Sachinidis A, Govaere O, Roskams T, De Boe V, Vanhaecke T, Rogiers V (2014) Human skin-derived stem cells as a novel cell source for in vitro hepatotoxicity screening of pharmaceuticals. Stem Cells Dev 23:44-55

Sasaki M, Yoshimura-Miyakoshi M, Sato Y, Nakanuma Y (2015) A possible involvement of endoplasmic reticulum stress in biliary epithelial autophagy and senescence in primary biliary cirrhosis. J Gastroenterol 50:984-995

Sharanek A, Burban A, Burbank M, Le Guevel R, Li R, Guillouzo A, Guguen-Guillouzo C (2016) Rho-kinase/myosin light chain kinase pathway plays a key role in the impairment of bile canaliculi dynamics induced by cholestatic drugs. Sci Rep 6:24709

Tan KP, Wood GA, Yang M, Ito S (2010) Participation of nuclear factor (erythroid 2-related), factor 2 in ameliorating lithocholic acid-induced cholestatic liver injury in mice. Br J Pharmacol 161:1111-1121
Van den Hof WF, Ruiz-Aracama A, Van Summeren A, Jennen DG, Gaj S, Coonen ML, Brauers K, Wodzig WK, van Delft JH, Kleinjans JC (2015) Integrating multiple omics to unravel mechanisms of cyclosporin A induced hepatotoxicity in vitro. Toxicol In Vitro 29:489-501

Vatakuti S, Olinga P, Pennings JL, Groothuis GM (2017) Validation of precision-cut liver slices to study drug-induced cholestasis: a transcriptomics approach. Arch Toxicol 91:1401-1412

Villeneuve DL, Crump D, Garcia-Reyero N, Hecker M, Hutchinson TH, LaLone CA, Landesmann B, Lettieri T, Munn S, Nepelska M, Ottinger MA, Vergauwen L, Whelan M (2014) Adverse outcome pathway (AOP) development I: strategies and principles. Toxicol Sci 142:312-320

Vinken M (2013) The adverse outcome pathway concept: a pragmatic tool in toxicology. Toxicology 312:158-165

Vinken M (2015) Adverse outcome pathways and drug-induced liver injury testing. Chem Res Toxicol 28:1391-1397

Vinken M (2016) Adverse outcome pathways as tools to assess druginduced toxicity. Methods Mol Biol 1425:325-337

Vinken M, Landesmann B, Goumenou M, Vinken S, Shah I, Jaeschke H, Willett C, Whelan M, Rogiers V (2013) Development of an adverse outcome pathway from drug-mediated bile salt export pump inhibition to cholestatic liver injury. Toxicol Sci 136:97-106

Vinken M, Knapen D, Vergauwen L, Hengstler JG, Angrish M, Whelan M (2017) Adverse outcome pathways: a concise introduction for toxicologists. Arch Toxicol 91:3697-3707

Wagner M, Zollner G, Trauner M (2009) New molecular insights into the mechanisms of cholestasis. J Hepatol 51:565-580

Wolters JE, van Herwijnen MH, Theunissen DH, Jennen DG, Van den Hof WF, de Kok TM, Schaap FG, van Breda SG, Kleinjans JC (2016) Integrative "-omics" analysis in primary human hepatocytes unravels persistent mechanisms of cyclosporine A-induced cholestasis. Chem Res Toxicol 29:2164-2174

Woolbright BL, Jaeschke H (2012) Novel insight into mechanisms of cholestatic liver injury. World J Gastroenterol 18:4985-4993

Woolbright BL, Antoine DJ, Jenkins RE, Bajt ML, Park BK, Jaeschke H (2013) Plasma biomarkers of liver injury and inflammation demonstrate a lack of apoptosis during obstructive cholestasis in mice. Toxicol Appl Pharmacol 273:524-531

Woolbright BL, Dorko K, Antoine DJ, Clarke JI, Gholami P, Li F, Kumer SC, Schmitt TM, Forster J, Fan F, Jenkins RE, Park BK, Hagenbuch B, Olyaee M, Jaeschke H (2015) Bile acid-induced necrosis in primary human hepatocytes and in patients with obstructive cholestasis. Toxicol Appl Pharmacol 283:168-177

Woolbright BL, McGill MR, Yan H, Jaeschke H (2016) Bile acidinduced toxicity in HepaRG cells recapitulates the response in primary human hepatocytes. Basic Clin Pharmacol Toxicol 118:160-167

Xu JJ, Diaz D, O’Brien PJ (2004) Applications of cytotoxicity assays and pre-lethal mechanistic assays for assessment of human hepatotoxicity potential. Chem Biol Interact 150:115-128

Yang K, Köck K, Sedykh A, Tropsha A, Brouwer KL (2013) An updated review on drug-induced cholestasis: mechanisms and investigation of physicochemical properties and pharmacokinetic parameters. J Pharm Sci 102:3037-3057

Zollner G, Trauner M (2006) Molecular mechanisms of cholestasis. Wien Med Wochenschr 156:380-385

Zollner G, Trauner M (2008) Mechanisms of cholestasis. Clin Liver Dis 12:1-26 